\title{
What Role for Probiotics in Necrotising Enterocolitis
}

\author{
Arthur C. Ouwehand ${ }^{1, *}$ \\ ${ }^{1}$ Active Nutrition, DuPont Nutrition and Health, Kantvik, Finland \\ ${ }^{*}$ Corresponding author: Arthur C. Ouwehand, Active Nutrition, DuPont Nutrition and Health, 02460 Kantvik, Finland. Tel: +358-405956353, Fax: +358-104315601, E-mail: Arthur.ouwe- \\ hand@dupont.com.
}

Received: September 17, 2013; Accepted: October 19, 2013

Keywords: Enterocolitis, Necrotizing; Lactobacillus; Bifidobacterium

Necrotising enterocolitis (NEC) is estimated to be the most prevalent emergency of the gastrointestinal tract in the neonates (1). The overall incidence of NEC is approximately 1 in 1000 live births, but in infants less than 1500 $\mathrm{g}$, the incidence increases to between $3 \%$ and $10 \%$ (2). The pathogenesis of NEC is likely to be multifactorial with an important microbial component to it. The intestinal microbiota of preterm infants is less diverse than that of term infants and appears to be more commonly colonised by potential pathogenic species from genera such as Klebsiella, Enterobacter and Clostridium $(3,4)$.

Surgery does not seem to have a major effect on morbidity and mortality associated with NEC. Probiotics, however, appear to hold promise. According to the most widely accepted definition, probiotics are: live microorganisms which when administered in adequate amounts confer a health benefit on the host (5). Several meta-analyses have been published in the past few years. The conclusions of these meta-analyses vary, however, from probiotics prevent severe NEC and all-cause mortality in preterm infants (6-9) to no effect or limited effect of probiotics on NEC morbidity or mortality, but some positive indications of symptoms are associated with NEC $(10,11)$. Thus, more recent meta-analyses appear to have more modest conclusions. In any case, the consumption of probiotics by neonates appears to be safe and has not been reported to cause septicaemia. It therefore appears that more recent studies investigating the effect of probiotics on NEC are yielding less convincing results.

To this end, Sanaei and co-workers (12)report in this issue of the journal on a study with a combination of probiotic strains to reduce the risk of NEC in very low birth weight infants. In the study, where 136 infants were included; no difference in NEC or sepsis was observed between the probiotic and placebo group. Total NEC incidence was $13 \%$. However, the incidence of severe NEC (stages II and III) was low (three cases; i.e. $2 \%$ ) and less than what has been reported in other studies (6); this may be a reason why no difference observed. As no power calculation was reported, it is not known what the authors were expecting for incidence or effect size. The administered dose varied from $5 \times 10^{8}$ to $10^{9} \mathrm{CFU} / \mathrm{d}$ depending on the weight of the infant. The authors suggest this may have been too low to induce an effect; however, some studies have been using even lower doses and still observed an effect $(13,14)$. While it maybe, it is not certain that this is indeed a cause for the lack of a protective effect. The study product is mentioned, but not in any great detail; what were strains contained in the product and at what levels? More important, no rationale is given for choosing the used product. The strain combination appears to have been tested in non-fatty liver disease (15) and as complementary therapy in Helicobacter eradication (16) with mixed results and this is not linked to any expected benefits in NEC.

Thus, there are a number of potential reasons why no effect was observed in the study by Sanaei and co-workers (12). Similar challenges have been reported by Li and coworkers (17) where a mean NEC (stage II and III) incidence of $2.6 \%$ was observed. These studies do not necessarily cast any doubt upon the optimistic view of probiotics' possibilities to reduce the incidence of NEC (18). It is unfortunate that the authors did not emphasise the positive side of their study; NEC incidence was low in their cohorts; much lower then what is commonly referred to; that is really good news.

Where does this leave us? With no other effective treatments available, should probiotics have the benefit of the doubt? Probiotics have never been reported to cause any septicaemia in this very sensitive population and can thus be considered safe. Furthermore, selected probiotics have been reported to reduce the risk for NEC and associated problems. However, it is not realistic to expect that any probiotic strain or combination of strains will reduce NEC risk; a selection based on known properties

Copyright (c) 2014, Pediatric Infections Research Center. This is an open-access article distributed under the terms of the Creative Commons Attribution-NonCommercial 4.0 International License (http://creativecommons.org/licenses/by-nc/4.0/) which permits copy and redistribute the material just in noncommercial usages, provided the original work is properly cited. 
and earlier performance is essential. Thus, while further research is ongoing; with sufficiently powered studies and carefully selected strains, specific probiotics or combinations of probiotics could be considered as a complementary prophylaxis in very low birth weight infants for the reduction of NEC risk.

\section{Authors' Contribution}

The author wrote the manuscript and is solely responsible for it's content.

\section{Financial Disclosure}

The author is an employee of DuPont Nutrition and Health. DuPont Nutrition and Health manufactures and sells probiotics.

\section{References}

1. Reynolds RM, Thureen PJ. Special circumstances: trophic feeds, necrotizing enterocolitis and bronchopulmonary dysplasia. Semin Fetal Neonatal Med. 2007;12(1):64-70.

2. Dominguez KM, Moss RL. Necrotizing enterocolitis. Clin Perinatol. 2012;39(2):387-401.

3. Stewart CJ, Marrs EC, Magorrian S, Nelson A, Lanyon C, Perry JD, et al. The preterm gut microbiota: changes associated with necrotizing enterocolitis and infection. Acta Paediatr. 2012;101(11):1121-7.

4. Poyser NL. Effects of hydrocortisone, oestradiol and progesterone on A23187-stimulated prostaglandin output from the guinea-pig uterus superfused in vitro. Prostaglandins.1987;33(1):101-12.

5. FAO/WHO . Guidelines for the evaluation of probiotics in food. 2002. Available from: www.who.int/foodsafety/publications/fs_management/probiotics2/.

6. Alfaleh K, Anabrees J, Bassler D, Al-Kharfi T. Probiotics for prevention of necrotizing enterocolitis in preterm infants. Cochrane Database Syst Rev. 2011(3):CD005496.

7. Wang Q, Dong J, Zhu Y. Probiotic supplement reduces risk of necrotizing enterocolitis and mortality in preterm very low-birth- weight infants: an updated meta-analysis of 20 randomized, controlled trials. J Pediatr Surg. 2012;47(1):241-8.

8. Guthmann F, Kluthe C, Buhrer C. Probiotics for prevention of necrotising enterocolitis: an updated meta-analysis. Klin Padiatr. 2010;222(5):284-90.

9. Deshpande G, Rao S, Patole S, Bulsara M. Updated meta-analysis of probiotics for preventing necrotizing enterocolitis in preterm neonates. Pediatrics. 2010;125(5):921-30.

10. Bernardo WM, Aires FT, Carneiro RM, Sa FP, Rullo VE, Burns DA Effectiveness of probiotics in the prophylaxis of necrotizing enterocolitis in preterm neonates: a systematic review and metaanalysis. J Pediatr (Rio J). 2013;89(1):18-24.

11. Mihatsch WA, Braegger CP, Decsi T, Kolacek S, Lanzinger H, Mayer $B$, et al. Critical systematic review of the level of evidence for routine use of probiotics for reduction of mortality and prevention of necrotizing enterocolitis and sepsis in preterm infants. Clin Nutr. 2012;31(1):6-15.

12. Sanaei Dashti A, Abolfazl Afjeh S, Basiry A, Shirvani F, Seifi K, Mohammad Taheri Z. Prophylactic Probiotics for Prevention of Necrotizing Enterocolitis (NEC) in Low Birth Weight Neonates. Arch Pediatr Infect Dis. 2013;1(4):174-9.

13. Dani C, Biadaioli R, Bertini G, Martelli E, Rubaltelli FF. Probiotics feeding in prevention of urinary tract infection, bacterial sepsis and necrotizing enterocolitis in preterm infants. A prospective double-blind study. BiolNeonate. 2002;82(2):103-8.

14. Stratiki Z, Costalos C, Sevastiadou S, Kastanidou O, Skouroliakou M, Giakoumatou A, et al. The effect of a bifidobacter supplemented bovine milk on intestinal permeability of preterm infants. Early Hum Dev. 2007;83(9):575-9.

15. Shavakhi A, Minakari M, Firouzian H, Assali R, Hekmatdoost A Ferns G. Effect of a Probiotic and Metformin on Liver Aminotransferases in Non-alcoholic Steatohepatitis: A Double Blind Randomized Clinical Trial. Int J Prev Med. 2013;4(5):531-7.

16. Shavakhi A, Tabesh E, Yaghoutkar A, Hashemi H, Tabesh F, Khodadoostan $\mathrm{M}$, et al. The effects of multistrain probiotic compound on bismuth-containing quadruple therapy for Helicobacter pylori infection: a randomized placebo-controlled triple-blind study. Helicobacter. 2013;18(4):280-4.

17. Li D, Rosito G, Slagle T. Probiotics for the prevention of necrotizing enterocolitis in neonates: an 8-year retrospective cohort study. J Clin Pharm Ther. 2013: [Epub ahead of print].

18. Shane AL, Deshpande GC, Merenstein D. Improved neonatal outcomes with probiotics. JAMA Pediatr. 2013;167(10):885-6. 